\title{
O SENTIDO ÉTICO DOS CONCEITOS DE NADA E LIBERDADE EM SARTRE E KRISHNAMURTI
}

The ethic meaning of nothingness and freedom's conceptions in Sartre and Krishnamurti

Roust Rosa Vieira *

Resumo: O presente trabalho visa elucidar questões referentes ao conceito de liberdade, de Jean-Paul Sartre, de forma vinculada às discussões do filósofo indiano Jiddu Krishnamurti no campo ético, moral e do autoconhecimento. Sartre (2005) afirma, no último capítulo de seu ensaio de ontologia fenomenológica $O$ ser $e$ o nada, que não é da alçada da ontologia formular prescrições morais. No entanto, suas ideias a respeito da liberdade humana e da responsabilidade supõem uma ética e uma possibilidade de escolha moral para o homem. Neste sentido, esta breve pesquisa se propõe a investigar como as principais ideias de Sartre repercutem na filosofia de Krishnamurti, adquirindo um sentido explicitamente ético. O presente trabalho apresentará a tese fundamental de Sartre de que o Ego é um objeto transcendente à consciência, e como tal, por conseguinte, ele não se encontra nem formalmente nem materialmente na consciência, mas que é um ser existente no mundo, quer dizer, um ser que revela-se sempre como um objeto transcendente visado pela consciência. A proposição do cogito pré-reflexivo, em Sartre, que indica que a consciência é uma imanência absoluta, isto é, de que ela é vazia de todo conteúdo, remete explicitamente às concepções de Krishnamurti no domínio da subjetividade originária, das relações entre o observador e a coisa observada. Krishnamurti assume o ponto de vista fenomenológico ao tratar dos atos de reflexão, de pensamento, como transcendentes visados por uma consciência em pleno estado de lucidez, de espontaneidade. Tal como Sartre, ele afirma deste modo a liberdade absoluta da consciência humana com relação ao Ego.

Palavras-chave: Sartre. Krishnamurti. Ego.

\begin{abstract}
The present work aims to elucidate issues concerning to Jean-Paul Sartre freedom's conception linked to the Indian philosopher Jiddu Krishnamurti discussions on the field of ethic, moral and self-knowledge. Sartre (2005) states, at the last chapter of his essay of phenomenological ontology Being and nothingness that the ontology itself cannot formulate ethical precepts. Nevertheless, his ideas on human freedom and responsibility bring to mind an ethic and a moral choice's possibility to mankind. In this sense, this brief research proposes itself investigate how Sartre's main ideas reflect on Krishnamurti philosophy, acquiring a very explicitly ethical meaning. This work will present Sartre's fundamental thesis that Ego is a transcendent object to consciousness, and such as, hence, it is not formally nor materially at the consciousness at all, but it is situated at the existential dominium, i.e., it is always revealed as an transcendent object posit by consciousness. The pre-reflective cogito proposal, in Sartre, which indicates that consciousness is an absolute immanence, i.e., that it is empty from all contents, makes explicitly reference to Krishnamurti conceptions on the field of original subjectivity, on relationship between the observer and observed thing. Krishnamurti assumes the phenomenological point of view as he discusses on reflection acts, thoughts, as transcendent objects posit by a consciousness in broad state of lucidity, of spontaneity. Such as Sartre, he states like that consciousness absolute freedom in relation to Ego.
\end{abstract} Keywords: Sartre. Krishnamurti. Ego. Freedom. Ethic.

Liberdade. Ética.

* Mestrado pela Universidade Federal de Uberlândia - marcelroust@hotmail.com.

\begin{tabular}{|c|c|l|l|c|c|}
\hline intuitio & $\begin{array}{c}\text { ISSN } \\
1983-4012\end{array}$ & Porto Alegre & Vol.8 $-\mathrm{N}^{\circ} .2$ & $\begin{array}{c}\text { Dezembro } \\
2015\end{array}$ & p.76-93 \\
\hline
\end{tabular}




\section{Relação entre consciência e intencionalidade: a tese husserliana}

Os temas centrais da filosofia de Sartre como o nada, a transcendência do ego, a liberdade, o projeto original, no contexto do existencialismo, apontam para a concepção de que a existência do Para-si precede e comanda a essência, e que, por conseguinte, o homem encontra-se em plena liberdade no exercício de suas ações. Em seu artigo de revisão psicológica A transcendência do ego, Sartre apresenta pela primeira vez sua famosa distinção entre consciência irrefletida e consciência reflexiva; tal distinção, por sua vez, viria a fundamentar posteriormente os principais conceitos de $O$ ser e o nada tais como o do Em-si, o Para-si, a negação, a liberdade, que constituem a base principal de todas as descobertas sartrianas no campo da fenomenologia. No seu discurso $O$ existencialismo é um humanismo, Sartre esclarece de forma simples tais conceitos, referindo-se à ideia do nada como o fato da consciência humana não possuir uma essência a priori, quer dizer, no homem a existência precede a essência, o que significa que ele existe primeiro e só depois se escolhe, se projeta; neste processo, o homem é absolutamente livre para escolher sua essêncial.

É na ideia de consciência transcendental, que surge no início do século 20 com o método fenomenológico de Edmund Husserl, que Sartre encontra a principal referência filosófica para elaborar suas concepções. A liberdade em Sartre já aparece desde sempre relacionada a esta subjetividade transcendental; isto significa que tal liberdade só é possível em uma consciência que seja uma absoluta transcendência com relação ao mundo. Para a fenomenologia sartriana, a liberdade deriva do campo imanente da consciência, constitui para esta uma estrutura originária, fundamental, e é a partir desta concepção que Sartre constrói suas teorias sobre o ser. Precisamos discutir primeiramente, então, a forma como se dá a relação entre a consciência transcendental e o mundo na fenomenologia husserliana, para depois compreender como tal relação permite a Sartre identificar ontologicamente a existência humana com o estado de não-ser e a liberdade.

Para Husserl ${ }^{2}$, a consciência transcendental é o domínio último e apodítico no qual se encontra o ego cogito. A transcendência designa o fato de que todos os objetos do mundo são transcendentes à consciência, ou seja, eles são projetados como existentes no espaço exterior, e a consciência se transcende justamente para alcançá-los lá fora, para estabelecer com eles uma relação de contato direto, de presença a. A consciência existe numa esfera de transcendência absoluta, mas ela é dotada da capacidade de alcançar o objeto em si mesmo, de revelá-lo na exata posição que ele ocupa no mundo. É uma relação entre sujeito e objeto em que o objeto comparece "em pessoa" para a consciência, e a consciência tem dele

\footnotetext{
${ }^{1}$ SARTRE, Jean Paul. O existencialismo é um humanismo. Tradução de Rita Correia Guedes. Paris: Les Éditions Nagel, 1970.

${ }^{2}$ HUSSERL, Edmund. Méditations Cartésiennes. Traduit par Gabrielle Peiffer et Emmanuel Lévinas. Paris: Librairie Philosophique J.Vrin, 1953.
}

\begin{tabular}{|c|c|c|c|c|c|}
\hline intuitio & $\begin{array}{c}\text { ISSN } \\
1983-4012\end{array}$ & Porto Alegre & Vol.8 $-\mathrm{N}^{\circ} .2$ & $\begin{array}{c}\text { Dezembro } \\
2015\end{array}$ & p.76-93 \\
\hline
\end{tabular}


uma intuição real e imediata ${ }^{3}$. A consciência, transcendendo-se para fora de si, posiciona o objeto como existente no mundo, e cada ato pelo qual ela visa tal objeto emana de seu campo transcendental.

Segundo Husserl ${ }^{4}$, a consciência transcendental é o campo original e irredutível do qual procede toda experiência possível na vida psicológica. Dotada desse caráter transcendental, a consciência existe como uma absoluta presença a si, ela é consciência de si própria, mas se revela como um ego totalmente puro, espontâneo, que se volta para o mundo em cada um dos seus modos de perceber, de lembrar, de julgar, de conhecer, etc. O próprio eu psicofísico, nesta concepção, é também objetivado pela consciência, e, por conseguinte, pertence ao domínio do mundo material, concreto. Deste modo, concebe-se a consciência como anterior à própria vida empírica e psíquica, ela precede qualquer existência objetiva, permanecendo como pura imanência de si a si.

Por conseguinte, de fato, a existência natural do mundo - do mundo do qual eu posso falar - pressupõe, como uma existência em si anterior, aquela do ego puro e de suas cogitationes. O domínio de existência natural não tem, portanto, senão uma autoridade de segunda ordem e pressupõe sempre o domínio transcendental $5^{5}$.

Explicitado o sentido imanente da transcendência, Husserl estabelece a relação entre consciência e mundo baseando-se no conceito de intencionalidade. Segundo Lévinas ${ }^{6}$, este conceito tem origem na filosofia escolástica e significa basicamente dirigir-se para, visar alguma coisa. Em Husserl ${ }^{7}$, a intencionalidade designa o fato de que toda consciência é consciência de alguma coisa. Toda percepção é percepção de algo, e a consciência assume a existência real do objeto na medida em que lhe toma como objeto de uma intenção. Cada estado intencional da consciência visa o objeto à sua maneira: a percepção de uma mesa, por exemplo, assume determinada mesa individual; a lembrança dessa mesa, por sua vez, assume a mesa como lembrança; e o mesmo vale para a imaginação, que assume a imagem; e em seguida a ideia, o desejo, o juízo de valor, etc. De acordo com Husserl:

é preciso ampliar o conteúdo do ego cogito transcendental, lhe acrescentar um elemento novo e dizer que todo cogito, ou ainda todo estado de consciência

${ }^{3}$ HUSSERL, Edmund. Méditations Cartésiennes. Traduit par Gabrielle Peiffer et Emmanuel Lévinas. Paris: Librairie Philosophique J.Vrin, 1953.

${ }^{4}$ HUSSERL, Edmund. Méditations Cartésiennes. Traduit par Gabrielle Peiffer et Emmanuel Lévinas. Paris: Librairie Philosophique J.Vrin, 1953.

5 «Par conséquent, en fait, l'existence naturelle du monde - du mond dont je puis parler - présuppose, comme une existence en soi antérieur, celle de l'ego pur et de ses cogitationes. Le domaine d'existence naturelle n'a donc qu'une autorité de second ordre et présuppose toujours le domaine transcendental » (HUSSERL, Edmund. Méditations Cartésiennes. Traduit par Gabrielle Peiffer et Emmanuel Lévinas. Paris: Librairie Philosophique J.Vrin, 1953, p. 18).

${ }^{6}$ LÉVINAS, Emmanuel. Théorie de l'intuition dans La Phénoménologie de Husserl. Paris: Librairie Philosophique J.Vrin, 1994.

${ }^{7}$ HUSSERL, Edmund. Méditations Cartésiennes. Traduit par Gabrielle Peiffer et Emmanuel Lévinas. Paris: Librairie Philosophique J.Vrin, 1953.

\begin{tabular}{|c|c|l|l|c|c|}
\hline intuitio & $\begin{array}{c}\text { ISSN } \\
1983-4012\end{array}$ & Porto Alegre & Vol.8 $-\mathrm{N}^{\mathrm{o}} .2$ & $\begin{array}{c}\text { Dezembro } \\
2015\end{array}$ & p.76-93 \\
\hline
\end{tabular}


«visa» alguma coisa, e que ele carrega em si mesmo, enquanto «visado» (enquanto objeto de uma intenção) seu cogitatum respectivo ${ }^{8}$.

A estrutura da consciência é a intencionalidade. A intencionalidade é considerada então a própria essência da consciência e um dos conceitos mais importantes para a fenomenologia. "L'intentionalité se presente comme l'essence même de la conscience (...) réalise un concept premier et fondamental pour le commencement de la phénoménologie" ". O que Husserl estabelece como intencionalidade envolve um fluxo temporal de estados e vivências que se caracteriza pela imanência e pela capacidade de outorgar significado às coisas do mundo. É impossível um ato da consciência que não vise um objeto, a consciência é sempre consciência de. Compreende-se a consciência, portanto, não como uma substância pensante, mas como uma atividade constituída por atos de percepção, lembrança, volição, imaginação, juízos de valor e outros, que se dirigem sobre os objetos do mundo, conferindo a cada um deles seu significado particular. A consciência visa sempre alguma coisa a partir deste conjunto de atos intencionais, por conseguinte, ela possui uma estrutura imanente que constitui o mundo ao atribuir sentido aos acontecimentos da vida cotidiana $^{10}$.

Tendo em consideração a intencionalidade como estrutura essencial da consciência, Husserl passa a elaborar a concepção de que a consciência comporta uma temporalidade própria. A questão do tempo é analisada pelo filósofo de modo articulado ao problema da intencionalidade, do modo como a consciência constitui cada objeto dado intencionalmente. Pelo processo de constituição temporal, o objeto adquire um sentido, um significado para a consciência. Percebe-se que tal ocorre através daquilo que Husserl ${ }^{11}$ denomina de síntese dos estados vividos, ou seja, a forma de ligação essencial que une um estado de consciência a outro, conferindo ao objeto uma identidade única em meio à multiplicidade de aspectos (Abschattungen) em que ele aparece. Para Husserl, a identificação do objeto é possível na medida em que a consciência realiza a síntese de todas as aparições do objeto no tempo (percepção visual, tátil, sonora, lembrança, representação, expectativa), de modo que a consciência sabe que é do mesmo objeto que se trata em cada modalidade de apreensão. Husserl, em textos como o das Méditationes Cartésiennes, desenvolve a tese de uma consciência interna contínua do tempo, reportando-se ao fato de que todo estado vivido dura, transcorre, se temporaliza enquanto consciência de. A síntese é, então, a unidade do

\footnotetext{
${ }^{8}$ «Il faudra élargir le contenu de l'ego cogito transcendental, lui ajouter un élément nouveau et dire que tout cogito ou encore tout état de conscience «vise» quelque chose, et qu'il porte en lui même, en tant que «visé» (en tant qu'objet d'une intention) son cogitatum respectif » HUSSERL, Edmund. Méditations Cartésiennes. Traduit par Gabrielle Peiffer et Emmanuel Lévinas. Paris: Librairie Philosophique J.Vrin, 1953, p. 28.

${ }^{9}$ LÉVINAS, Emmanuel. Théorie de l'intuition dans La Phénoménologie de Husserl. Paris: Librairie Philosophique J.Vrin, 1994, p. 77.

${ }^{10}$ HUSSERL, Edmund. Méditations Cartésiennes. Traduit par Gabrielle Peiffer et Emmanuel Lévinas. Paris: Librairie Philosophique J.Vrin, 1953.

${ }^{11}$ HUSSERL, Edmund. Méditations Cartésiennes. Traduit par Gabrielle Peiffer et Emmanuel Lévinas. Paris: Librairie Philosophique J.Vrin, 1953.
}

\begin{tabular}{|c|c|c|c|c|c|}
\hline intuitio & $\begin{array}{c}\text { ISSN } \\
1983-4012\end{array}$ & Porto Alegre & Vol.8 $-\mathrm{N}^{\mathrm{o} .2}$ & $\begin{array}{c}\text { Dezembro } \\
2015\end{array}$ & p.76-93 \\
\hline
\end{tabular}


cogitatum (o objeto pensado), que permanece identicamente o mesmo em meio à multiplicidade de aspectos, de faces, de perfis, com que tal objeto é apreendido continuamente pelo cogito.

Todo estado vivido tem sua duração vivida. Se se trata de um estado de consciência do qual o cogitatum é um objeto do mundo - como na percepção do cubo -, é a ocasião de distinguir a duração objetiva que aparece (por exemplo, aquela do cubo) da duração interna do processo da consciência (por exemplo, aquela da percepção do cubo). Esta transcorre em períodos e fases temporais que são suas, e que são elas mesmas apresentações, se modificando duma forma contínua, de um só e mesmo cubo. Sua unidade é aquela de uma síntese. Ela não é uma simples ligação contínua de cogitationes por assim dizer exteriormente unidas umas às outras, mas ela é a unidade de uma só consciência, e nesta consciência se constitui a unidade de uma entidade (Gegenstandlichkeit) intencional, precisamente como era a mesma entidade se apresentando de maneiras variadas e múltiplas ${ }^{12}$.

A consciência possui, portanto, uma temporalidade própria, uma duração interna, contínua, transcorrendo de forma progressiva no seu campo transcendental. É por meio desta temporalidade que ela pode visar de diferentes maneiras o mesmo objeto, dando ao curso da percepção outras direções, ou então através da lembrança (representação do objeto) retida na memória. O fluxo de estados de consciência envolve múltiplas possibilidades perceptivas, cada uma delas apresentando o mesmo objeto sob um ângulo diferente. Husserl chama a atenção para o fato de que, em cada percepção, o objeto só aparece por Abschattungen, por faces, por perfis, o que significa que os outros lados dele permanecem escondidos, imersos "na sombra". No entanto, cada estado de consciência apresenta um horizonte intencional, a capacidade de antecipar os lados ainda não percebidos do objeto, realizando uma conexão da percepção presente com a percepção que ainda está por vir. Assim, a consciência realiza a síntese das percepções já dadas com aquelas que ainda estão em vias de se concretizar. Este processo temporal libera em bloco todos os horizontes que compõe o objeto; nele, a consciência pode traçar previamente as potencialidades deste objeto, preenchê-lo e captá-lo, assim, como um polo único de identidade.

Na percepção imediata do cubo, por exemplo, o que se apresenta primeiramente aos olhos é uma pirâmide, mas Husserl ${ }^{13}$ mostra que o aspecto atual remete sempre às faces ainda não reveladas, e a consciência caracteriza-se por poder antecipar todos os horizontes possíveis do objeto, conferindo-lhe a

\footnotetext{
12 «Tout étàt vécu a sa durée vécue. S'il s'agit d'un état de conscience dont le cogitatum est un objet du monde comme dans la perception du cube - Il y a lieu de distinguer la durée objective qui apparatt (par exemple, celle de ce cube) de la durée «interne» du processus de la conscience (par exemple, celle de la perception du cube). Celle-ci s'« écoule» en des périodes et des phases temporelles qui sont siennes, et qui sont elles-mêmes des présentations, se modifiant d'une façon continue; du seul et même cube. Leur unité est celle d'une synthèse. Elle n'est pas une simple liaison continue de cogitatîones pour ainsi dire extérieurement accolêes les unes aux autres, mais elle est une unité de conscience une, et dans cette conscience se constitue l'unité d'une entite (Gegenstandlichkeit) intentionnelle; précisément comme étant la même entité se présentant de manières variées et multiples » (HUSSERL, Edmund. Méditations Cartésiennes. Traduit par Gabrielle Peiffer et Emmanuel Lévinas. Paris: Librairie Philosophique J.Vrin, 1953, p. 36).

${ }^{13}$ HUSSERL, Edmund. Méditations Cartésiennes. Traduit par Gabrielle Peiffer et Emmanuel Lévinas. Paris: Librairie Philosophique J.Vrin, 1953.
}

\begin{tabular}{|c|c|c|c|c|c|}
\hline intuitio & $\begin{array}{c}\text { ISSN } \\
1983-4012\end{array}$ & Porto Alegre & Vol.8 $-\mathrm{N}^{\circ} .2$ & $\begin{array}{c}\text { Dezembro } \\
2015\end{array}$ & p.76-93 \\
\hline
\end{tabular}


sua identidade verdadeira. O sentido objetivo do objeto, segundo Husserl, nunca é dado no cogito atual, que só apreende um esboço, um espectro, um único perfil da coisa, no entanto, a consciência dá-se conta da totalidade que está presente de maneira implícita em cada aparição do objeto. A consciência pode extrair de cada horizonte seu sentido objetivo, interrogá-lo, explicá-lo, revelar suas potencialidades, e constituir a partir dele uma entidade unificada. É verdade que as faces ainda não reveladas do cubo permanecem indeterminadas de início, no entanto, a consciência possui sempre certa "estrutura de determinação" que lhe permite constituir previamente o cubo como uma totalidade idêntica, acabada, antes mesmo de perceber nele qualidades particulares como de comprimento, cor e textura.

\section{A transcendência do eu: a temporalidade como falta de ser}

Todas as principais concepções da fenomenologia, fundada por Husserl, viriam a exercer ampla influência em Sartre ao longo de toda sua carreira filosófica, contudo, isto não significa que haja total confluência de pensamento entre os dois autores. Sartre leva as discussões sobre a consciência para o plano ontológico, indagando a respeito do sentido do ser em geral. Por conseguinte, a liberdade é analisada por ele como uma estrutura originária, primordial e inerente à realidade humana. A estrutura temporal da consciência, porém, é que permite a Sartre identificar a consciência com o nada, conferindolhe o estatuto ontológico de não-ser, a negação, a liberdade absoluta. Para Sartre ${ }^{14}$, é pela consciência humana que o nada e a liberdade anunciam-se no mundo.

Para elaborar estes que seriam os princípios básicos do existencialismo, Sartre assume as concepções fenomenológicas de transcendência e intencionalidade, no entanto, ele acaba rompendo com a ideia de um ego transcendental defendida por Husserl. Segundo Sartre ${ }^{15}$, Husserl não permaneceu fiel à sua concepção de intencionalidade, pois havia retomado no livro As ideias, a "tese clássica de um Eu transcendental que estaria como que por detrás de cada consciência". A intencionalidade, ao contrário, exige que a consciência exista em um campo absolutamente transcendental; este campo, nesta condição, é vazio e impessoal, ou seja, não há um "eu” que o fundamente, uma vez que todo "eu" só existe na estrutura "consciência do eu"; o Ego, portanto, só aparece no nível da reflexão, surgindo sobre um fundo de consciência que ele não contribui para criar. Na consciência não há uma identidade a priori, pelo contrário, todos os tipos de identidade existem para ela. O que isto significa? Que toda identidade que ali aparece só existe na condição de "consciência de identidade", e que, portanto, a consciência já se desprendeu do ser da identidade no próprio ato em que se fez consciência dele, em que lhe constituiu como objeto.

${ }^{14}$ SARTRE, Jean Paul. L'être et le néant. Paris: Éditions Gallimard, 1943.

${ }^{15}$ SARTRE, Jean Paul. A transcendência do ego. Tradução de Pedro M. S. Alves. Lisboa: Edições Colibri, 1994, p. 96.

\begin{tabular}{|c|c|c|c|c|c|}
\hline intuitio & $\begin{array}{c}\text { ISSN } \\
1983-4012\end{array}$ & Porto Alegre & Vol.8 $-\mathrm{N}^{\circ} .2$ & $\begin{array}{c}\text { Dezembro } \\
2015\end{array}$ & p.76-93 \\
\hline
\end{tabular}


Ao assumir tais proposições, Sartre entra em confronto com a tradição filosófica, que desde Descartes atribui centralidade ao "eu", tornando-o um fundamento seguro para o conhecimento. De acordo com $\mathrm{Machado}^{16}$, a rejeição sartriana da centralidade do "eu" fundamenta-se na oposição à quase totalidade da Filosofia Ocidental Moderna, a qual concedeu ao "eu" posição privilegiada, seja por intermédio do cogito cartesiano "Eu penso, logo existo", seja em Kant, que conferiu ao "eu" o estatuto de condição lógica das representações. Para Sartre ${ }^{17}$, o cogito se dá sempre por ocasião de um ato reflexivo. A intencionalidade, que indica que a consciência é sempre uma consciência de, permite a Sartre fazer a distinção entre duas formas de consciência: a consciência irrefletida, de primeiro grau, que apreende como objeto transcendente uma segunda consciência, a consciência reflexiva. O cogito, deste modo, não apareceria senão através de uma operação reflexiva, em um ato de pensamento dirigido ao Eu. O "eu", o "mim", o Ego, nascem na consciência refletida por ocasião de um ato reflexivo. A consciência é pura espontaneidade, no entanto, ela modifica-se a si própria por meio do pensamento reflexivo, tornando-se pessoal, adquirindo neste ato a personalidade de um "eu".

A consciência de primeiro grau, chamada por Sartre de cogito pré-reflexivo, é despojada então de todo conteúdo, passando a existir num campo transcendental vazio, evanescente. A transcendência em Sartre adquire deste modo o sentido de falta de ser, de ausência: a consciência já não se identifica mais com o mundo, é colocada à distância dele, caracterizando-se exatamente por realizar uma cisão, uma ruptura com os modos de ser deste mundo. Esta ruptura significa que a consciência, que traz em si o nada, o vazio, diferencia-se totalmente dos objetos materiais, psíquicos e orgânicos, os quais são chamados de Em-si na terminologia sartriana. O Em-si designa o ser que é plenamente si mesmo, na total positividade. $\mathrm{O}$ ser do Em-si corresponde à objetividade de sua existência, quer dizer, ele possui o atributo de existir como uma coisa plena, atual, concreta. O ser consolida o Em-si de ponta a ponta, fundindo-o consigo mesmo, conferindo-lhe uma identidade. Isto significa que tal ser já se revelou desde sempre pronto, acabado, definitivo; ele se coagulou neste ser, se solidificou neste ser, permanecendo assim sempre idêntico a si mesmo. É por isso que é fácil defini-lo: "é o céu”, “é uma cadeira”, "é um carro", ou então, “é o prazer", "é o ódio", "é o ciúme”, porque sua essência está contida nele de antemão. O objeto é Em-si quando se trata de um tipo de ser opaco, maciço, que coincide na plena identidade consigo mesmo, possui uma essência fixa, acabada, e dele nada mais pode se afirmar a não ser que é o que é.

Tornado consciência, o ser sofre uma cisão em tal identidade, já não possui mais uma essência a priori, convertendo-se deste modo num Para-si. Sartre ${ }^{18}$ usa a expressão Para-si para salientar o fato de que a consciência não possui a densidade plena de um Em-si, ela é infestada constantemente por um nada,

${ }^{16}$ MACHADO, Fabiane Schneider. O ego como problema existencial em Sartre. Dissertação de mestrado. Santa Maria, RS: UFSM 2011.

${ }^{17}$ SARTRE, Jean Paul. A transcendência do ego. Tradução de Pedro M. S. Alves. Lisboa: Edições Colibri, 1994.

${ }^{18}$ SARTRE, Jean Paul. L'être et le néant. Paris: Éditions Gallimard, 1943.

\begin{tabular}{|c|c|l|l|c|c|}
\hline intuitio & $\begin{array}{c}\text { ISSN } \\
1983-4012\end{array}$ & Porto Alegre & Vol.8 $-\mathrm{N}^{\mathrm{o}} .2$ & $\begin{array}{c}\text { Dezembro } \\
2015\end{array}$ & p.76-93 \\
\hline
\end{tabular}


um vazio, uma falta de ser, por isso, deve projetar-se sempre para além de si mesma. Como o campo transcendental necessita da reflexão para adquirir uma identidade, Sartre ${ }^{19}$ conclui que o Para-si só existe numa distância de si a si, quer dizer, ao fazer-se consciente de si mesmo, o Para-si desagrega-se de seu ser, ele põe-se à distância, numa lonjura, num perpétuo afastamento, e só dali pode contemplar-se como reflexo de si próprio. No campo imanente onde se encontra, a consciência é pura translucidez; tal como um espelho que reflete o mundo, ela só mostra, mas nunca deixa-se mostrar. A consciência caracteriza-se, portanto, por manter uma relação de si para consigo mesma, num processo que Sartre denomina como díade reflexo-refletidor.

Sartre refere-se nesta expressão a um jogo de reflexos que esboça-se na consciência toda vez que procuramos captar o seu ser. A consciência, neste jogo, é um reflexo que é ao mesmo tempo refletidor: "se tentamos apreendê-la como refletidora, ela se desvanece e recaímos no reflexo" ${ }^{20}$. O reflexivo, deste modo, está separado do refletido por um nada, um vazio infinitesimal, num processo de desdobramento em que o Para-si perde-se lá fora, e instantaneamente, tenta recuperar o seu ser. Para Sartre, o Para-si está condenado a buscar perpetuamente o seu ser em outro lugar, "no refletidor, caso se faça reflexo, no reflexo, caso se coloque como refletidor" ${ }^{\text {21 }}$. Nessa dualidade está em questão o fato de que o ser da consciência não pode coincidir consigo mesmo numa adequação plena, tal como ocorre com o Em-si. Ser consciente é sofrer uma descompressão interna em que o ser desgarra-se da consciência e passa a existir somente enquanto refletido, o que já supõe uma distância da consciência com relação a tal ser.

O homem padece de uma instabilidade interna, ele está forçosamente separado de seu ser exatamente pelo nada que o habita ${ }^{22}$. O Para-si consiste, portanto, numa negação do mundo, já que a consciência nega o instante atual, nadifica o momento presente no próprio ato em que busca a si própria lá longe, na imagem refletida de si. Diferente do Em-si, que é plena positividade, o Para-si transcende a situação imediata em direção $a$, por isso, ele é o ser pelo qual a negatividade vem ao mundo. A consciência existe desde a origem escapando de si mesma; ela constitui um futuro em relação ao qual seu ser aparece como falta de, por conseguinte, existir para ela consiste numa fuga de si, num escapar-se rumo às suas possibilidades projetadas lá adiante. A consciência projeta-se temporalmente através dessa díade reflexo-refletidor: em qualquer momento que procuramos captá-la, ela já está adiante de si, no futuro, ou atrás de si, no passado. Em si mesma, ela é um nada, uma fissura interna, uma insuficiência de ser; por

\footnotetext{
${ }^{19}$ SARTRE, Jean Paul. L'être et le néant. Paris: Éditions Gallimard, 1943.

20 «...si nous tentons de la saisir comme réfléchissant, elle s'évanouit et nous retombons sur le reflet» (SARTRE, Jean Paul. L'être et le néant. Paris: Éditions Gallimard, 1943, p. 112).

${ }^{21}$ « ...dans le reflétant s'il se fait reflet, dans le reflet s'il se pose comme reflétant » (SARTRE, Jean Paul. L'être et le néant. Paris: Éditions Gallimard, 1943, p. 188).

${ }^{22}$ BELO, Renato Santos Belo. O paradoxo da liberdade: psicanálise e história em Sartre. Dissertação de mestrado. São Paulo: USP 2006.
}

\begin{tabular}{|c|c|c|c|c|c|}
\hline intuitio & $\begin{array}{c}\text { ISSN } \\
1983-4012\end{array}$ & Porto Alegre & Vol.8 $-\mathrm{N}^{\circ} .2$ & $\begin{array}{c}\text { Dezembro } \\
2015\end{array}$ & p.76-93 \\
\hline
\end{tabular}


isso, a busca instantânea pelo refletido é a perspectiva de realizar-se, de adquirir afinal a plena adequação consigo mesma ${ }^{23}$.

O Para-si é portanto definido, ao longo do texto de $O$ ser e o nada, como o ser que não é o que é e é o que não é. O Para-si não é o que é porque ele se transcende a todo momento em direção ao refletido, colocando-se deste modo à distância de si. Paradoxalmente, o Para-si é o que não é porque ele é o refletidor que faz existir o refletido, ele tem-de-ser este ser com o qual não coincide justamente para transcendê-lo, para nadificá-lo. É o que Sartre chama de facticidade do Para-si: o homem encontra-se desde sempre em situação, ele é operário ou burguês, nasceu em determinado país, em determinada família, condição física, social, etc. Entretanto, todas as operações do Para-si, na imaginação, na ideia, na lembrança, na expectativa, tendem a nadificar tal facticidade, o que é, para atingir justamente o que não é. O Para-si encontra-se sempre num estado de inacabamento em relação ao ser refletido. De acordo com Perdigão, "a separação interna do Para-si faz dele uma espécie de ser inacabado, ao qual está sempre faltando alguma coisa para se completar e preencher o seu miolo"24.

Levando em conta esta dualidade reflexo-refletidor no bojo do Para-si, a temporalidade aparece então como dimensão fundamental desta relação que a consciência mantém consigo mesma. Em sua analítica existencial, antes mesmo de Sartre, Heidegger ${ }^{25}$ chegou também à conclusão de que a realidade humana existe como temporalização, ela temporaliza o tempo do mundo, e é em seu horizonte que se manifesta a história. Isto ocorre pelo que Heidegger denomina os três êxtases da temporalidade: passado, presente e futuro. Sartre conclui do mesmo modo que "a Temporalidade é o ser do Para-si na medida em que este tem de sê-lo extaticamente. A Temporalidade não é, mas o Para-si se temporaliza existindo"26.

Os três êxtases temporais só podem ser concebidos como o modo de existir da consciência, a qual, enquanto Para-si, tem-de-ser seu ser à distância de si, refletido extaticamente no passado e no futuro. A relação extática do homem com o tempo, além disso, mostra que o Para-si não pode, evidentemente, "ter" um passado ou futuro do mesmo modo como ele possui um objeto físico. Para Sartre, não é possível neste caso haver uma relação de exterioridade em que o Para-si, existindo no presente, mantenha com o passado e o futuro um vínculo externo ao modo do possuidor que lança mão de um objeto possuído. Tem de haver uma conexão fundamental entre o Para-si e o tempo, e simplesmente supor uma relação de posse significa cortar as pontes entre os dois. Sartre $^{27}$ salienta que as expressões "ter um passado" e "ter um futuro" devem ser substituídas então por "ser seu próprio passado e ser seu futuro". O passado é a

\footnotetext{
${ }^{23}$ SARTRE, Jean Paul. L'être et le néant. Paris: Éditions Gallimard, 1943.

${ }^{24}$ PERDIGÃO, Paulo. Existência e liberdade: uma introdução à filosofia de Sartre. Porto Alegre: L\&PM, 1995, p. 44.

25 HEIDEGGER, Martin. Ser e tempo. Tradução de Marcia Sá Cavalcante Schuback. Petrópolis: Editora Vozes, 2005.

${ }^{26}$ SARTRE, Jean Paul. L'être et le néant. Paris: Éditions Gallimard, 1943, p.192.

${ }^{27}$ SARTRE, Jean Paul. L'être et le néant. Paris: Éditions Gallimard, 1943.
}

\begin{tabular}{|c|c|l|l|c|c|}
\hline intuitio & $\begin{array}{c}\text { ISSN } \\
1983-4012\end{array}$ & Porto Alegre & Vol.8 $-\mathrm{N}^{\mathrm{o} .2}$ & $\begin{array}{c}\text { Dezembro } \\
2015\end{array}$ & p.76-93 \\
\hline
\end{tabular}


O sentido ético dos conceitos de nada e liberdade em Sartre e Krishnamurti

característica de um ser que, ao existir, tem-de-ser lá atrás seu passado, um ser em que está em questão seu ser passado numa síntese original. O Para-si sustenta seu ser passado, é responsável por ele. É por isso que o homem pode se orgulhar ou se envergonhar de algo que fez no passado. O fenômeno temporal é antes de tudo individual. Não há como falar de passado sem atribuí-lo à condição de passado de alguém ou para alguém. E neste caso até mesmo passado de uma sociedade, um país, etc. Como enfatiza Sartre ${ }^{28}$, o passado anuncia aquilo que o homem é, porque é através do homem que o passado vem ao mundo.

A consciência manifesta-se temporalmente junto às coisas, e o passado constitui para ela o conhecimento que torna possível qualquer relação com tais coisas: o passado é o sentido deste utensílio que a consciência reconhece como estando aí para isto, é reportando-se ao passado que a consciência recorda um rosto familiar, etc. Todavia, o Para-si só existe no passado ao modo do ser que não é o que é e é o que não é, por conseguinte, ele não é mais o que foi, uma vez que sua liberdade nadifica o passado como não-ser. Mas como o Para-si não pode extinguir ou modificar este ser passado, ele continua sendo o que era, ele conserva tal passado em si ao modo do refletidor que faz existir o reflexo. Sartre ressalta que é justamente pelo fato do Para-si ser seu passado que ele pode, na mesma medida, não sê-lo.

A conexão entre ser e não-ser só pode ser interna: é no ser enquanto ser que deve despontar o não-ser, é no não-ser que deve surgir o ser, e isso não poderia ser um fato, uma lei natural, e sim um surgimento do ser que é seu próprio nada de ser. Assim, portanto, se não sou meu próprio passado, isso não se dá pelo modo originário do devir, mas na medida em que tenho-de-sê-lo para não sê-lo e que tenho-de-não-sê-lo para sê-lo. Isso deve nos esclarecer a natureza do modo "era": se não sou o que era, isso não ocorre porque já tenha mudado, o que faria supor um tempo já dado, mas sim porque sou, com relação a meu ser, à maneira de uma conexão interna de não sê-lo (...) é inclusive esta necessidade de ser meu passado o único fundamento possível do fato de que não o sou ${ }^{29}$.

O futuro, da mesma maneira, é o modo do Para-si ser o que ainda não é. De acordo com Perdigão $^{30}$, só existe futuro possível porque o Para-si faz existir esse futuro como algo que ele já é no presente. Isto significa que o Para-si já é desde sempre seu futuro, porque é o futuro que sustenta o ser que ele pretende realizar; o futuro é o ser que o Para-si ainda não é, mas que já existe no presente como projeto, como sentido de suas ações de agora. Para Sartre, o passado e o futuro é que conferem significado às condutas do Para-si no presente, é essa totalidade temporal que dá sentido às suas vivências cotidianas.

${ }^{28}$ SARTRE, Jean Paul. L'être et le néant. Paris: Éditions Gallimard, 1943.

${ }^{29}$ «La liaison de l'être et du non-être ne peut être qu'interne : c'est dans 1 'être en tant qu'être que doit surgir le non être, dans le non-être que 1 'être doit pointer et ceci ne saurait être un fait, une loi naturelle, mais un surgissement de l'être qui est son propre néant d'être. Si donc je ne suis pas mon propre passé, ce ne peut être sur le mode originel du devenir, mais en tant que j'ai à l'être pour ne pas l'être et que j'ai à ne pas l'être pour l'être. Ceci doit nous éclairer sur la nature du mode «étais » : si je ne suis pas ce que j 'étais, ce n'est pas parce que j'ai déjà changé, ce qui supposerait le temps déjà donné, c'est parce que je suis par rapport à mon être sur Le mode de liaison interne du n'être-pas. (...) c'est même cette nécessité d'être mon passé qui est le seul fondement possible du fait que je ne le suis pas » (SARTRE, Jean Paul. L'être et le néant. Paris: Éditions Gallimard, 1943, p. 152).

${ }^{30}$ PERDIGÃO, Paulo. Existência e liberdade: uma introdução à filosofia de Sartre. Porto Alegre: L\&PM, 1995.

\begin{tabular}{|c|c|l|l|c|c|}
\hline intuitio & $\begin{array}{c}\text { ISSN } \\
1983-4012\end{array}$ & Porto Alegre & Vol.8 $-\mathrm{N}^{\mathrm{o}} .2$ & $\begin{array}{c}\text { Dezembro } \\
2015\end{array}$ & p.76-93 \\
\hline
\end{tabular}


"Se me lanço em uma ação, só posso fazê-lo porque no passado imediato testemunhei o meu intento de realizá-la, e porque o futuro me guia como esse projeto a realizar" ${ }^{\text {"31 }}$. O futuro é a dimensão para a qual se arremessa o Para-si com a intenção de fundir-se consigo mesmo, adquirindo um ser que seria a síntese de seu presente com o futuro que lhe falta.

A consciência temporaliza-se numa dispersão original, escapando de si rumo a si mesma. Ela constitui a imagem plena de si mesma adiante de si, e apreende-se como perpétuo inacabamento em relação a esse ser. A consciência, portanto, é uma falta de ser que lhe infesta de momento a momento. É por essa falta, porém, que o Para-si atribui sentido às coisas do mundo: uma nuvem escura vista por ele constitui-se no presente como chuva-prestes-a-cair, o meio disco da lua já aparece imediatamente como plenilúnio, a semente é vista como flor na iminência de desabrochar, etc. As potencialidades do mundo são percebidas pelo Para-si na medida em que ele se transcende em direção ao futuro, e é nesse processo mesmo que ele volta ao presente para conferir à nuvem, à semente e à lua o seu respectivo significado. $\mathrm{O}$ conceito de projeto nos permite compreender a maneira como o homem atribui sentido às suas ações ao ultrapassá-las em direção ao porvir. Ao empenhar-se em uma atividade, o Para-si já está desde sempre no futuro, junto à obra concluída, a qual constitui o sentido e a motivação de cada ação realizada no presente $^{32}$.

\section{O nada como fundamento da ação e da liberdade}

As concepções sartrianas de tempo mostram que a consciência só se constitui na ação. Sartre chama a atenção dos psicólogos para o fato de que consciência e ação identificam-se completamente. Para o homem, "ser reduz-se a fazer"; nada está pronto na realidade humana, nem o temperamento, nem o caráter, nem as paixões, nem a personalidade, porque estes atributos só podem manifestar-se na conduta propriamente dita do sujeito. Não são objetos já dados no psíquico, é o sujeito mesmo que, ao agir, realiza em si uma determinada maneira de agir que somente a posteriori podemos designar como seu temperamento, suas inclinações, suas tendências, etc. A ambição, a covardia, a irascibilidade, o ciúme, por exemplo, não são características inatas, antes, são modos de se comportar em tal ou qual circunstância, maneiras de responder a determinadas situações. "Assim, a realidade humana não é primeiro para agir depois; para a realidade humana, ser é agir, e deixar de agir é deixar de ser”, o que significa também que sua própria "determinação à ação é, ela mesma, ação"33.

\footnotetext{
${ }^{31}$ PERDIGÃO, Paulo. Existência e liberdade: uma introdução à filosofia de Sartre. Porto Alegre: L\&PM, 1995, p. 71.

${ }^{32}$ SARTRE, Jean Paul. L'être et le néant. Paris: Éditions Gallimard, 1943.

${ }^{33}$ SARTRE, Jean Paul. O ser e o nada. Tradução de Paulo Perdigão. Petrópolis, RJ: Vozes, 2005, p. 587.
}

\begin{tabular}{|c|c|c|c|c|c|}
\hline intuitio & $\begin{array}{c}\text { ISSN } \\
1983-4012\end{array}$ & Porto Alegre & Vol.8 $-\mathrm{N}^{\circ} .2$ & $\begin{array}{c}\text { Dezembro } \\
2015\end{array}$ & p.76-93 \\
\hline
\end{tabular}


Na concepção sartriana, a alma não pode existir à maneira de uma substância pensante, um "eu" constituído na plena identidade consigo mesmo, o qual, ao aparecer no mundo, se encarregaria da função de "animar" um corpo. Sartre ${ }^{34}$ conclui, pelo contrário, que a existência da consciência é ação de ponta a ponta; por conseguinte, a "alma" não é senão um processo de animação pura, algo que só existe em ato, em plena atividade. Não podemos afirmar simplesmente que a consciência é do mesmo modo como dizemos que a pedra é, a árvore é, etc. A consciência não é, ela está sendo, e sob tal condição, está sujeita a encarregar-se da própria função de existir; é na ação, portanto, que a consciência subsiste, que a consciência persevera na existência. Como disse Heidegger a respeito do Dasein, a consciência é o único ser em que está em questão o seu próprio ser. Mesmo os modos, as qualidades presentes na realidade humana, são ações que a consciência realiza: o homem só pode ser reflexivo, ser afetuoso, ser ciumento, ser calmo, ser colérico, na medida em que assume determinadas condutas, escolhas, atitudes, com relação aos objetos que lhe são dados intencionalmente. Isto significa que o homem responsabiliza-se pela Autoria de seu próprio ser, e não existe senão por intermédio das ações que ele próprio coloca em exercício no mundo.

Não há uma natureza humana pronta e, por isso, o homem tenta construí-la através de seu próprio projeto de ser. No entanto, a consciência nunca chega a alcançar a identidade de um Em-si. Como Para-si, observou Sartre, a consciência nunca chega a possuir uma essência porque toda essência é, por definição, uma consciência de essência, e a consciência assim volta a escapar transcendentalmente: ela não se converte, ela apenas visa. A consciência não é o que é e é o que não é no sentido de que todo conteúdo que existe para-a-consciência só pode existir na condição de objeto visado pela consciência ${ }^{35}$. A consciência só reflete o Em-si que ela tem-de-ser para logo em seguida nadificá-lo, perdendo-se num estado perpétuo de não-ser. Dizer que a consciência é o nada significa que ela reflete as coisas, como um espelho, mas nunca chega a se converter na coisa refletida, nunca adquire a substancialidade da coisa refletida.

A metáfora do espelho ilustra bem a condição do Para-si de ser um nada e sempre fracassar no seu projeto de ser. O espelho reflete, projeta, reproduz, mas o espelho não existe em si mesmo, todo o seu sentido se encontra na coisa refletida. Poderíamos ver o mundo inteiro no espelho, no entanto, não nos é dado ver de nenhuma forma o espelho em si, o espelho não existe, ele aparece apenas enquanto reflexo de outras coisas que não são ele, que estão fora dele. Não é possível jamais captar o espelho como sendo alguma coisa. Como espelho que só reflete o mundo, a consciência nunca é forçada ou obrigada a ser nada

\footnotetext{
${ }^{34}$ SARTRE, Jean Paul. L'être et le néant. Paris: Éditions Gallimard, 1943.

${ }^{35}$ SARTRE, Jean Paul. O ser e o nada. Tradução de Paulo Perdigão. Petrópolis, RJ: Vozes, 2005.
}

\begin{tabular}{|c|c|c|c|c|c|}
\hline intuitio & $\begin{array}{c}\text { ISSN } \\
1983-4012\end{array}$ & Porto Alegre & Vol.8 $-\mathrm{N}^{\circ} .2$ & $\begin{array}{c}\text { Dezembro } \\
2015\end{array}$ & p.76-93 \\
\hline
\end{tabular}


de concreto, de substancial, ela nunca se sujeita à identidade de uma coisa, ela escapa, portanto, de toda determinação. Daí, a controversa afirmação de Sartre de que o homem está condenado a ser livre ${ }^{36}$.

\section{A liberdade como fundamento ético da ação}

Em Krishnamurti, essa condenação da consciência humana à liberdade adquire um novo significado, de conotação especificamente ética. A liberdade com relação a toda essência, a toda forma de determinismo, é que permite ao homem desenvolver uma plena lucidez de percepção, uma compreensão profunda de seus estados interiores, de seus conflitos psicológicos. Em diversos livros, discursos e palestras, Krishnamurti chama a atenção para a capacidade do homem de compreender profundamente os conflitos existentes em seu ego, em seus pensamentos, promovendo assim uma total mudança em sua estrutura psíquica. Para isto, é absolutamente necessário que a consciência seja completa liberdade com relação ao "eu". Neste sentido, Krishnamurti e Sartre entendem a consciência como uma absoluta transcendência às coisas (ego, emoções, volições, medos, lembranças), o que torna possível um estado humano de plena lucidez, de plena acuidade psicológica.

Conforme Krishnamurti ${ }^{37}$, a mente humana divide-se em mente condicionada e mente criadora. A mente condicionada, nesta perspectiva, vive na esfera do pensamento, deixando-se escravizar por hábitos mentais contraídos pela espécie humana ao longo de toda sua história. Por conseguinte, a mente condicionada é velha, mecânica, embotada, individual, egocêntrica. De certa forma, Krishnamurti comunga do ponto de vista de Bergson de que o pensamento é mecânico, programado, repetitivo. Por terse adaptado à ação sobre a matéria inerte, o pensamento tornou-se ele próprio um mero instrumento técnico, que responde de forma automática à novidade incessante do devir e da vida. Segundo Bergson, que aprofundou essa questão:

A inteligência, por procurar sempre reconstituir, e reconstituir com o dado, deixa fugir o que há de novo em cada momento duma história. Não admite o imprevisível. Rejeita tudo o que seja criação. O que satisfaz a nossa inteligência é uma consequência determinada, calculada em função de antecedentes determinados. (...) A causalidade que ela procura e acha em toda a parte exprime o próprio mecanismo da nossa indústria, no qual recompomos indefinidamente o mesmo com os mesmos elementos, no qual repetimos os mesmos movimentos para obter o mesmo resultado. (...) A inteligência, mesmo quando já não opera sobre a matéria bruta, segue os hábitos adquiridos nesta operação (...) se comporta invariavelmente como se estivesse fascinada pela contemplação da matéria inerte ${ }^{38}$.

\footnotetext{
${ }^{36}$ SARTRE, Jean Paul. O ser e o nada. Tradução de Paulo Perdigão. Petrópolis, RJ: Vozes, 2005.

${ }^{37}$ KRISHNAMURTI, Jiddu. Liberte-se do passado. Tradução de Hugo Veloso. São Paulo: Cultrix, 1969 apud SOARES, 2001.

${ }^{38}$ BERGSON, Henry. A evolução criadora. Tradução de Adolfo Casais Monteiro. Rio de Janeiro: Opera Mundi,
}

\begin{tabular}{|c|c|c|c|c|c|}
\hline intuitio & $\begin{array}{c}\text { ISSN } \\
1983-4012\end{array}$ & Porto Alegre & Vol.8 $-\mathrm{N}^{\circ} .2$ & $\begin{array}{c}\text { Dezembro } \\
2015\end{array}$ & p.76-93 \\
\hline
\end{tabular}


Bergson faz uma explícita alusão à mente condicionada neste trecho, o pensamento condicionado, que transfere para os diversos campos da vida (as relações humanas, a religião, a ciência, a metafísica, os valores, o conhecimento) os hábitos mecânicos contraídos no processo de adaptação da mente ao trabalho com a matéria inerte. A mente condicionada é uma modalidade de consciência funcional que imprime eficiência às ações práticas exercidas pelos homens cotidianamente. No entanto, essa modalidade

possui uma memória ancestral, que está armazenada nas velhas células cerebrais do homem. (...) É ela que produz, sustenta e legitima a ancestral crueldade humana, proveniente da escravidão à ilusão da separatividade - sentir-se pessoa particular - e ao querer ter poder sobre o outro, usufruindo-o para proveito próprio. (...) a mente velha - produzida, desenvolvida, legitimada e mantida pelo ser humano - é condicionada e a totalidade desse condicionamento é o "conhecido". Na sua concepção, essa mente está condicionada pela educação, pela religião, pelas ideologias, pelos dogmas, pelas tradições. Ele afirma que tal condicionamento, cultivado e legitimado pela humanidade, se traduz, também, enquanto sistema de tradições, dogmas, crenças, hábitos, ideologias, preconceitos, que aprisionam o ser humano na caverna do "eu" psicológico, ancestralmente programado. (...) Assim, o sentido que Krishnamurti dá às palavras mente velha condicionada refere-se ao processo total do pensamento condicionado do ser humano, expresso como "eu" psicológico, tempo psicológico, células cerebrais do "velho" cérebro, intelecto, conhecimento, desejo, medo psicológico, apego, dependência psicológica, onde estão inseridos os resíduos do passado ${ }^{39}$.

A mente criativa, por outro lado, supõe uma libertação deste processo de condicionamento, uma total ruptura com toda a carga cultural e histórica acumulada na mente humana ${ }^{40}$. Contudo, como conciliar a concepção de mente condicionada à ideia sartriana de liberdade absoluta? É verdade então que o homem escolhe livremente seu condicionamento? Não estamos caindo em contradição, pois o condicionamento é também uma questão de escolha; deixar-se condicionar representa para o homem uma atitude de má-fé, de mentira para consigo mesmo, do ponto de vista sartriano. Não devemos esquecer o fato de que o homem, quase sempre, escolhe o caminho mais fácil, mais cômodo. É sempre mais fácil submeter-se a uma autoridade do que questioná-la; o homem geralmente opta por aquilo que julga mais favorável e conveniente. Pode-se observar o modo como as pessoas tendem a se apoiar na desculpa do ego, da personalidade, para agir de má-fé em diversas situações antiéticas, porque deixar-se condicionar revela-se sempre mais cômodo para o homem do que entrar em conflito com a sociedade e com as outras pessoas, criando uma oposição às ideias e valores estabelecidos culturalmente. No entanto, como enfatiza Sartre ${ }^{41}$, cada homem é responsável por todos os outros homens; ao escolher-se, ele escolhe a humanidade inteira,

1971, p. 174-177.

${ }^{39}$ SOARES, Noemi Salgado. Sobre uma pedagogia para o autoconhecimento: diálogo com algumas concepções educacionais de Jiddu Krishnamurti. Tese de doutorado. Salvador: UFBA/FACED 2001, p. 119-121.

${ }^{40}$ KRISHNAMURTI, Jiddu. Liberte-se do passado. Tradução de Hugo Veloso. São Paulo: Cultrix, 1969.

${ }^{41}$ SARTRE, Jean Paul. $O$ existencialismo é um humanismo. Tradução de Rita Correia Guedes. Paris: Les Éditions Nagel, 1970.

\begin{tabular}{|c|c|l|l|c|c|}
\hline intuitio & $\begin{array}{c}\text { ISSN } \\
1983-4012\end{array}$ & Porto Alegre & Vol.8 $-\mathrm{N}^{\mathrm{o}} .2$ & $\begin{array}{c}\text { Dezembro } \\
2015\end{array}$ & p.76-93 \\
\hline
\end{tabular}


porque suas ações criam uma imagem de homem tal como ele quer idealmente que o homem seja. A responsabilidade do homem é tal que engloba todas as outras pessoas; cada indivíduo representa em si a humanidade.

Por conseguinte, há um sentido ético muito profundo no fato de que o homem é livre com relação ao seu próprio ego. Isto torna a escolha possível, porque não há uma essência a priori que determine as atitudes do homem, não há uma "natureza humana" prévia para a qual possamos recorrer para justificar ou desculpar nossos atos, eximindo-nos de nossa responsabilidade. Krishnamurti desenvolve amplamente esse sentido ético de uma consciência sem "eu", ou melhor, de uma consciência absolutamente livre com relação ao "eu". O cientista David Bohm, no prefácio do livro The limits of thought, ressalta o principal fato psicológico descoberto por Krishnamurti:

What Krishnamurti was seriously proposing is that all this disorder, which is the root cause of such widespread sorrow and misery, and which prevents human beings from properly working together, has its root in the fact that we are ignorant of the general nature of our own processes of thought. Or, to put it differently, it may be said that we do not see what is actually happening when we are engaged in the activity of thinking. Ordinarily, we tend to be aware mainly of the content of this thought rather than of how it actually takes place. One can illustrate this point by considering what happens when one is reading a book. Usually, one is attentive almost entirely to the meaning of what is being read. However, one can also be aware of the book itself, of its constitution as being made up out of pages that can be turned, of the printed words and of the ink, of the fabric of the paper, etc. Similarly, we may be aware of the actual structure and function of the process of thought, and not merely of its content ${ }^{42}$.

Bohm ilustra neste trecho o fato de que o homem deixa-se absorver de tal forma pelo pensamento que passa a não prestar a devida atenção no modo como o pensamento funciona, como o pensamento cria os conflitos, as dores, as ilusões, os medos, etc. É possível, porém, promover uma completa mutação em nossa estrutura psíquica, libertando-nos do sofrimento causado pelo pensamento. Esta liberdade se dá quando a consciência encontra-se em um estado de plena lucidez com relação ao pensamento, à memória,

42 “O que Krishnamurti está seriamente propondo é que toda esta desordem, a qual é a raiz do sofrimento e da miséria amplamente difundida pela vida humana, e que impede que os seres humanos possam propriamente entrar em comunhão, em harmonia, fundamenta-se no fato de que nós somos ignorantes da natureza geral de nossos próprios processos de pensamento. Ou, em outras palavras, deve-se dizer que nós não percebemos o que está realmente acontecendo quando estamos empenhados na atividade do pensamento. Ordinariamente, nós tendemos a tomar consciência somente do conteúdo deste pensamento e não do modo como o processo do pensamento, de fato, acontece. Pode-se ilustrar esta questão considerando o que ocorre quando alguém está lendo um livro. Geralmente, o leitor está atento inteiramente ao significado daquilo que lê. No entanto, ele poderia também focar sua atenção no livro em si mesmo, em sua constituição física, nas páginas que podem ser folheadas, nas palavras impressas, na tinta, no papel, etc. Do mesmo modo, nós devemos ter imediata consciência da estrutura da função dos processos de pensamento, e não meramente de seu conteúdo" (BOHM, David; KRISHNAMURTI, Jiddu. The limits of thought. Krishnamurti Foundation of America, 1982, p. 06).

\begin{tabular}{|c|c|l|l|c|c|}
\hline intuitio & $\begin{array}{c}\text { ISSN } \\
1983-4012\end{array}$ & Porto Alegre & Vol.8 $-\mathrm{N}^{\mathrm{o}} .2$ & $\begin{array}{c}\text { Dezembro } \\
2015\end{array}$ & p.76-93 \\
\hline
\end{tabular}


aos desejos e emoções. Essa lucidez, que envolve uma capacidade de atenção, de observação, uma sensibilidade e uma plena acuidade psicológica, é o que Krishnamurti denomina meditação.

$\mathrm{Na}$ atitude de meditação, para Krishnamurti ${ }^{43}$, não há nenhuma espécie de concentração técnica, há total ausência de disciplina, de ajustamento ou repressão. Esta atitude não é passiva e acomodada como pode parecer, a princípio. Ela implica grande sensibilidade, plena capacidade de atenção. A meditação não é o ato de concentrar-se, de se focar num ponto somente e rejeitar todo o resto do mundo. A meditação é um estado de alerta mental, de pleno percebimento das coisas, de compreensão da totalidade. Meditação significa compreender a realidade pela observação atenta de cada coisa que existe; não é expulsar alguns pensamentos e ficar com outros, é o ato simples e natural de acompanhar a mente para onde quer que ela vá, ver como ela trabalha, como ela funciona, como ela cria a mentira, a falácia, a ilusão. Na meditação, a consciência é sã, lúcida, equilibrada, alerta, e pode assim compreender cada um dos movimentos da mente e não se permitir ser influenciada por nenhum deles, tornando-se completamente livre com relação ao ego.

Meditação não é seguir um sistema; não é repetição e imitação constantes. Meditação não é concentração. Um dos truques de certos instrutores de meditação é insistirem em que os seus discípulos aprendam a concentração, ou seja, fixar a mente num pensamento e expulsar todos os outros pensamentos. (...) Significa que ficais empenhado numa contínua batalha entre a obrigação de vos concentrardes, a um lado, e a vossa mente, a outro lado, que se põe a fugir para outras e variadas coisas - quando, ao contrário, devemos estar atentos a cada movimento da mente, aonde quer que ela vá. (...) A meditação exige uma mente sobremodo vigilante; a meditação é a compreensão da totalidade da vida, na qual não existe mais nenhuma espécie de fragmentação. Meditação não é controle do pensamento, porque, quando o pensamento é controlado, gera conflito na mente; mas, quando se compreende a estrutura e origem do pensamento, o pensamento então não mais interfere. (...) Meditação é estar cônscio de cada pensamento e de cada sentimento, nunca dizer que ele é certo ou errado, porém simplesmente observar e acompanhar seu movimento. Nessa vigilância, compreendeis o movimento total do pensamento e do sentimento ${ }^{44}$.

Tal como Nietzsche, Krishnamurti critica o fato de que o homem criou uma imagem de si muito superior ao que ele consegue ser. Esta imagem idealizada de homem, expressa na religião, na arte, na filosofia, na ciência, provoca em nós profundo sofrimento ao confrontarmos constantemente tal imagem de perfeição com o que na verdade somos. De acordo com Krishnamurti ${ }^{45}$, é possível viver em paz com o que é, com a realidade. Podemos observar a nós mesmos sem nenhuma espécie de conclusão, de condenação, de justificação, exatamente da forma como somos, olharmos para os nossos sentimentos e pensamentos da maneira como eles se manifestam, de momento a momento, observá-los atentamente, acompanhar cada um dos seus passos no interior de nosso ser, sem tentar explicar nada, sem tentar dividir

\footnotetext{
${ }^{43}$ KRISHNAMURTI, Jiddu. Obras completas. Buenos Aires: Kier, 1995.

${ }^{44}$ KRISHNAMURTI, Jiddu. Liberte-se do passado. Tradução de Hugo Veloso. São Paulo: Cultrix, 1969, p. 102103.

${ }^{45}$ KRISHNAMURTI, Jiddu. Sobre Deus. Tradução de Cecília Casas. São Paulo: Cultrix, 1992.
}

\begin{tabular}{|c|c|l|l|c|c|}
\hline intuitio & $\begin{array}{c}\text { ISSN } \\
1983-4012\end{array}$ & Porto Alegre & Vol.8 $-\mathrm{N}^{\circ} .2$ & $\begin{array}{c}\text { Dezembro } \\
2015\end{array}$ & p.76-93 \\
\hline
\end{tabular}


ou confrontar com qualquer teoria, sem desejo de mudança ou repressão, apenas reparar como determinado estímulo nasce, como ele funciona; ter a percepção clara de tudo que ocorre em nós. Quando a mente desenvolve tal tipo de consciência, ela já não faz nada com relação aos conflitos do pensamento, ela somente olha para eles, repara, compreende, tornando-se, enfim, completamente livre, porque não há mais perturbação em si, não há mais incômodo, só a clara compreensão de todo o processo.

"Viver com plenitude no momento presente é viver com o que é, o real, sem idéia de condenação ou justificação; então o compreendeis tão completamente que ficais livre dele. Quando se vê claramente, o problema está resolvido" ${ }^{46}$. Quando a mente se torna penetrante, capaz de viva atenção, de seriedade, ela pode ver e entender as coisas, imediatamente. Compreender cabalmente um fato é ficar livre dele, na medida em que compreendemos de maneira completa, plena, mais conscientes ficamos e mais livres com relação aos condicionamentos presentes no fato. Só ficamos livres do pensamento quando somos capazes de acompanhá-lo, de compreendê-lo momento após momento, para onde quer que ele vá; ter uma percepção aguçada, dinâmica, viva, de todo o processo psicológico. Deste modo, podemos ver como o sofrimento nasce, como o conflito surge dentro de nós, e não somos influenciados por tais sentimentos de maneira alguma.

Dispensar nossa completa atenção a um fato significa que não somos influenciados por ele, porque compreendemos como ele funciona. Não estou, no entanto, reagindo ao fato, não estou negando o fato nem me opondo a ele. Minha mente, em completo estado de alerta, de vigilância, apenas compreende o fato e, por conseguinte, torna-se livre com relação a ele. Eu observo a violência, a avidez, o ciúme, a inveja, o egoísmo, que fazem parte de mim, daí a proposta de Krishnamurti ${ }^{47}$ de que o observador e a coisa observada são um só. Se eu começo a condenar meus sentimentos a partir de valores morais, não significa que eu tenha sensibilidade para observar estes sentimentos, para acompanhar a forma com que eles se manifestam em mim, de momento a momento; para ter total percebimento de todo o processo psicológico que dá origem à violência, ao ciúme, tenho que estar vazio de qualquer julgamento, de qualquer explicação sobre a coisa, e simplesmente ver o fato, ver a realidade tal como ela é. A partir do momento em que consigo reparar no fato sem condená-lo, reprimi-lo ou justificá-lo, em que experimento integralmente o fato dispensando-lhe toda atenção de que sou capaz, desta hora em diante percebo que violência e ciúme são parte de mim, já não existe mais um $e u$ nem os sentimentos de um $e u$, a coisa é uma só, é um fato unitário, integrado, total; para Krishnamurti ${ }^{48}$, tal tipo de compreensão gera a liberdade, a redenção de todos os conflitos.

\footnotetext{
${ }^{46}$ KRISHNAMURTI, Jiddu. Sobre Deus. Tradução de Cecília Casas. São Paulo: Cultrix, 1992, p. 29.

${ }^{47}$ KRISHNAMURTI, Jiddu. Obras completas. Buenos Aires: Kier, 1995.

${ }^{48}$ KRISHNAMURTI, Jiddu. Obras completas. Buenos Aires: Kier, 1995.
}

\begin{tabular}{|c|c|c|c|c|c|}
\hline intuitio & $\begin{array}{c}\text { ISSN } \\
1983-4012\end{array}$ & Porto Alegre & Vol.8 $-\mathrm{N}^{\circ} .2$ & $\begin{array}{c}\text { Dezembro } \\
2015\end{array}$ & p.76-93 \\
\hline
\end{tabular}




\section{Referências}

BELO, Renato Santos Belo. O paradoxo da liberdade: psicanálise e história em Sartre. Dissertação de mestrado. São Paulo: USP 2006.

BERGSON, Henry. A evolução criadora. Tradução de Adolfo Casais Monteiro. Rio de Janeiro: Opera Mundi, 1971. BOHM, David; KRISHNAMURTI, Jiddu. The limits of thought. Krishnamurti Foundation of America, 1982.

HEIDEGGER, Martin. Ser e tempo. Tradução de Marcia Sá Cavalcante Schuback. Petrópolis: Editora Vozes, 2005.

HUSSERL, Edmund. Leçons pour une phénoménologie de la conscience intime du temps. Trad. Henri Dussort. Paris, Presses Universitaires de France, 1964.

HUSSERL, Edmund. Méditations Cartésiennes. Traduit par Gabrielle Peiffer et Emmanuel Lévinas. Paris: Librairie Philosophique J.Vrin, 1953.

KRISHNAMURTI, Jiddu. Sobre Deus. Tradução de Cecília Casas. São Paulo: Cultrix, 1992.

Liberte-se do passado. Tradução de Hugo Veloso. São Paulo: Cultrix, 1969. Obras completas. Buenos Aires: Kier, 1995.

LÉVINAS, Emmanuel. Théorie de l'intuition dans La Phénoménologie de Husserl. Paris: Librairie Philosophique J.Vrin, 1994.

MACHADO, Fabiane Schneider. O ego como problema existencial em Sartre. Dissertação de mestrado. Santa Maria, RS: UFSM 2011.

PERDIGÃO, Paulo. Existência e liberdade: uma introdução à filosofia de Sartre. Porto Alegre: L\&PM, 1995.

SARTRE, Jean Paul. A transcendência do ego. Tradução de Pedro M. S. Alves. Lisboa: Edições Colibri, 1994. . L'être et le néant. Paris: Éditions Gallimard, 1943.

. O ser e o nada. Tradução de Paulo Perdigão. Petrópolis, RJ: Vozes, 2005.

Éditions Nagel, 1970.

O existencialismo é um humanismo. Tradução de Rita Correia Guedes. Paris: Les

SOARES, Noemi Salgado. Sobre uma pedagogia para o autoconhecimento: diálogo com algumas concepções educacionais de Jiddu Krishnamurti. Tese de doutorado. Salvador: UFBA/FACED 2001.

Recebido em: 27/09/2014

Aprovado para a publicação em: 16/10/2015

\begin{tabular}{|c|c|l|l|c|c|}
\hline intuitio & $\begin{array}{c}\text { ISSN } \\
1983-4012\end{array}$ & Porto Alegre & Vol.8 $-\mathrm{N}^{\circ} .2$ & $\begin{array}{c}\text { Dezembro } \\
2015\end{array}$ & p.76-93 \\
\hline
\end{tabular}

